\title{
Escutando Rosa
}

\author{
WAGNER DIAS
}

$\mathrm{E}$ M “O BURRINHO PEDRÊs”, do livro Sagarana, de João Guimarães Rosa, podemos ouvir: "As ancas balançam, e as vagas de dorsos, das vacas e touros, batendo com as caudas, mugindo no meio, na massa embolada, com atritos de couros, estralos de guampas, estrondos e baques, e o berro queixoso do gado junqueira, de chifres imensos, com muita tristeza, saudade dos campos, querência dos pastos de lá do sertão...". Mais adiante, no mesmo texto, ainda se ouve: "Boi bem bravo. Bate baixo, bota baba, boi berrando... Dança doido, dá de duro, dá de dentro, dá direito...Vai, vem, volta, vem na vara, vai não volta, vai varando...”.

Essa dança das palavras aparece recorrente em toda a obra do escritor. Se seguirmos passos em Primeiras estórias, Corpo de baile, Grande sertão: veredas ou Magma, a sensação sonora se mantém. Podemos dizer que há momentos na literatura de Rosa em que se tornam muito audíveis os ruídos primordiais, sons de uma espécie de pré-música, ainda distante do período sacrificial de ordenação e de classificação em perspectiva modal e tonal, considerando aqui um breve período da história da música ocidental. ${ }^{1}$

Noutros momentos, nos textos de Guimarães, ritmos modais, melodias e harmonias são entregues ao leitor a partir de personagens e de lugares. A sonoridade pode ainda nos chegar à maneira terceiramargeana, isto é, situada no tempero e na mistura das duas margens visíveis do rio com a sua terceira, insondada, de comas e de ragas imaginários, ou ainda, por uma espécie de escape, num real intangível, fora da escrita musical, que só se ouve em suspeita, tal qual a oralidade dos aedos e dos antigos.

No trecho de Sagarana antes reproduzido, parece pertinente pensar numa representação ruidosa: de ancas, de dorsos, de estralos e de estrondos, de mugidos e de berros. Sem muito esforço, mais à frente, nesse mesmo recorte feito em "O burrinho pedrês", encontra-se a combinação rítmica, repetitiva, modal e ritual, na baba do boi bem bravo que bate baixo, o boi berrante.

Noutros cantos, noutros contos, inúmeras sugestões melódicas e harmônicas: nos olhos de Miguilim, no violão de Laudelim, na canção de Siruiz, na festa de Manuelzão, com procissão e oferenda a Nossa Senhora do Perpétuo Socorro, nos silvos e chiados de Sirimim, nas xurugações de Nhinhinha, na brancura misteriosa do polvilho em Maria Exita, na conversa dos bois, na valsa serena e desesperada do amor de Riobaldo e Diadorim, nos sons das invenções de Catraz, no recado cifrado do Morrão e na própria pirâmide do sertão.

Num sopro de palavras, aqui e acolá, Rosa também nos convida ao silêncio - como proposta de percepção de fenômenos inefáveis: das garatujas e das 
garabulhices infantis ao esboço do miraculoso. No conto "O espelho", em Primeiras estórias, o autor expõe: "tudo, aliás, é a ponta de um mistério. Inclusive, os fatos. Ou a ausência deles. Duvida? Quando nada acontece, há um milagre que não estamos vendo". Ao que estendemos para: Quando tudo é silêncio, há um milagre que se pode escutar. Em "A menina de lá", do mesmo Primeiras estórias, a personagem Nhinhinha nos tira o tempo todo o chão das convenções. Na sua voz o "Tatu não vê a lua", as "estrelinhas pia-pia", a "jabuticaba de vemme-ver" ou "o passarinho desapareceu de cantar".

No Grande sertão: veredas, o pacto de Riobaldo com o Sem Nome ora soa factível ora nebuloso: silencioso, ruidoso e berrante misturadamente. Por analogia, o pacto dos violeiros com o Cujo tem também as suas faces, sons e estórias que se desenham na cultura popular. Renato Andrade e Paulo Freire, como exemplos, são pactários ao modo de Urutu-Branco, isso não se duvida. E no enrosco de cordas dobradas vão evidenciando o que se vê e o que não se vê nas veredas e nos gerais sonoros. Em trio, são farinhas de mesmo saco e se reconhecem imediatos. Sem intermediários, na Taboca, no Urucuia ou em qualquer parte, acionam aquilo que tratamos de entender como a dor e o amor de ancestralidade, sons-condutos de inexplicável sentimento de universalidade de alma - ao mesmo tempo esmiuçadores de especialíssimos grotões.

Além disso, há na literatura roseana o manancial do cancioneiro. Há mesmo o "João fabulista", cancionista, "boi risonho": melódico, rítmico e fonético em exponencial. Reproduzimos aqui um ligeiro conceito de $O$ cancionista, de Luiz Tatit, em que ele diz existir boa diferença entre a voz que canta e a voz que fala. Em suas palavras "a voz que fala interessa-se pelo que é dito. A voz que canta, pela maneira de dizer". Mais que isso, "a melodia da fala não se estabiliza, não se repete e não adquire autonomia". Ao passo que a fala regida por leis musicais - frequiência e duração - ganha estabilidade, sentido próprio e se perpetua em movimento cíclico, como ritual.

Nesse sentido, considerando a noção de oralidade e seus pressupostos míticos, ou ainda a maneira pela qual as estórias são transmitidas no tempo e no espaço, na cultura, efeitos bastantes presentes nos textos de Guimarães Rosa, sugerimos que grande parte dos enredos roseanos se revela também em música cantada - para ser lembrada e entoada em verso e altura. Por esse curso dizemos então que Riobaldo, Sorôco, Manuelzão, Miguilim, Brejeirinha, Nhorinhá, Maria Mutema, Diadorim e tantas outras personagens falam, assoviam e cantam aos leitores, e isso nos mais variados timbres.

É fácil desmembrar daí as inquietações de compositores e intérpretes da nossa música quando deparam com a obra do autor. Se os sons todos - ruídos, melodias e formas lingüísticas - estão espalhados, tão abundantes, por toda parte dos escritos, então, o movimento é certo - criam-se e recriam-se formas de se cantar o sertão roseano. Seja à maneira de Caetano Veloso e Milton Nascimento, em A terceira margem do rio, de Gilberto Gil, em Casinha feliz, ou de Chico Buarque de Hollanda, em Assentamento. Seja por outros caminhos, como no da 


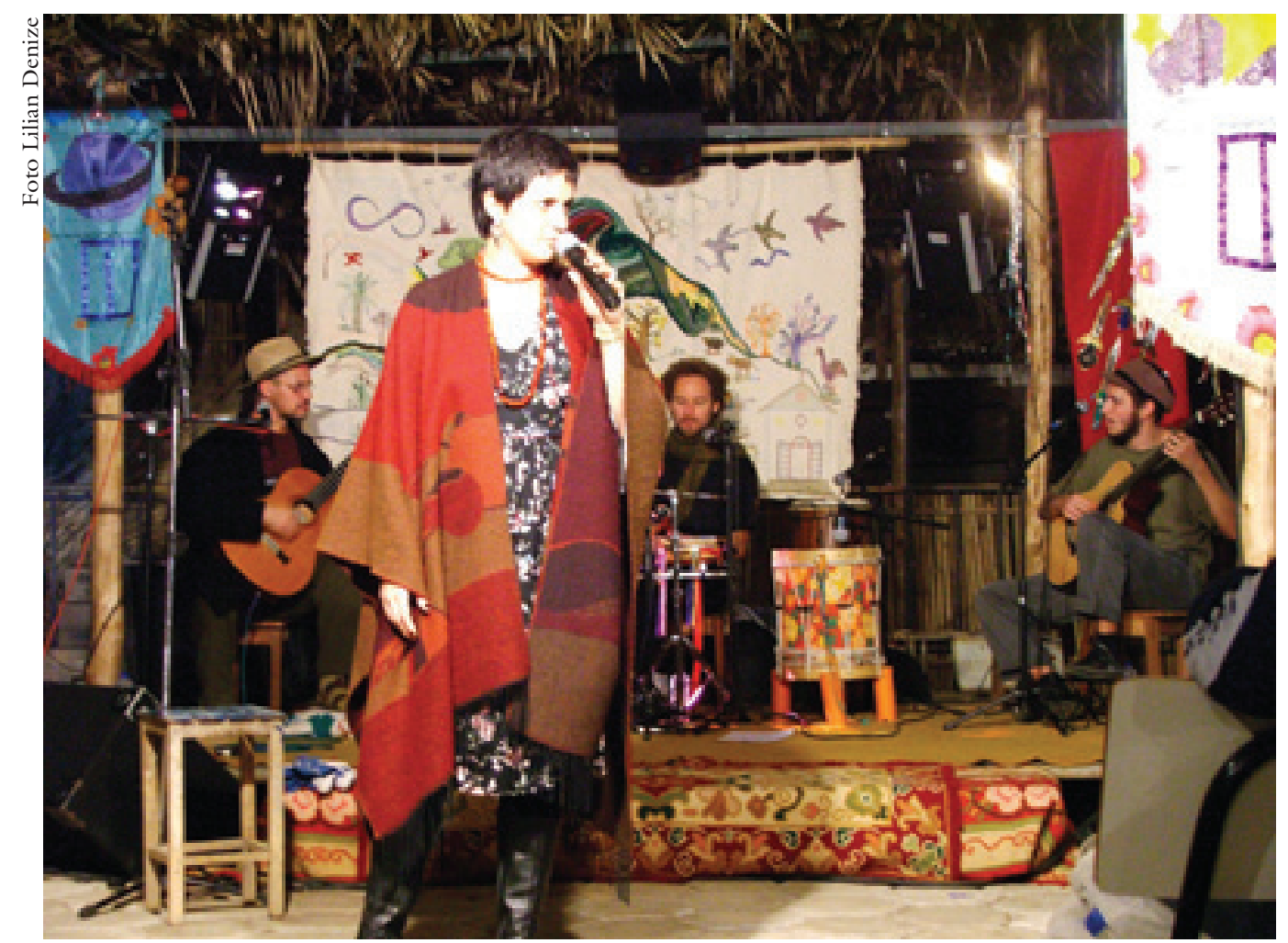

Show do Estúrdio Quarteto, em Morro da Garça (MG), em setembro de 2006.

montagem do espetáculo Romanço do boi bonito, sob direção musical de Jean Garfunkel, em que grupos como Nhambuzim, Estúrdio Quarteto, Babado de Chita e Contadores de Estórias Miguilim se reuniram para celebrar a festa de Manuelzão, ocasião do centenário de seu nascimento, em 2004.

Recentemente, muitos artistas têm se dedicado ao estudo da obra e às possibilidades musicais oferecidas por João Guimarães Rosa: Rodrigo Delage, músico de Belo Horizonte, descortina em sua viola a sonoridade despertada por Sagarana ou Grande sertão: veredas; Ivan Vilela sugere, entre tantas paisagens, uma valsa ao amor de Riobaldo e Diadorim; o grupo Nhambuzim, num canto a três vozes, reveste de carinho o aboio entoado pelo vaqueiro Manuelzão; o cantor Renato Braz, acompanhado de Nelson Ayres ao piano, acalanta o Rosa criança, em Menino quieto de Jean e Paulo Garfunkel; Elvis de Cordisburgo, ao modo maiêutico, descobre as melodias indicadas por Rosa e as reveste de trechos de textos que podem derivar de Magma, de Tutaméia ou de Ave, palavra, nas caminhadas literárias - da ponte da Quininha à Gruta do Maquiné; José Miguel Wisnik, com voz grave, mas de ressonância harmônico-aguda, desenrola sons de novelo do "sirgo fio das recordações"2 do jagunço Tatarana, o fim de "Maria Deodorina da Fé Bettancourt Marins - que nasceu para o dever de guerrear e nunca ter medo, e mais para muito amar, sem gozo de amor...".

Entre tantas insinuações em torno do tema, num quase "meio de redemunho”, músicos do Estúrdio Quarteto viajam pelas cidades de Morro da Garça, 
Andante

Som de passarim
$\mathrm{Am}^{7}$
Musica \& Letra: Wagner Dias

Em
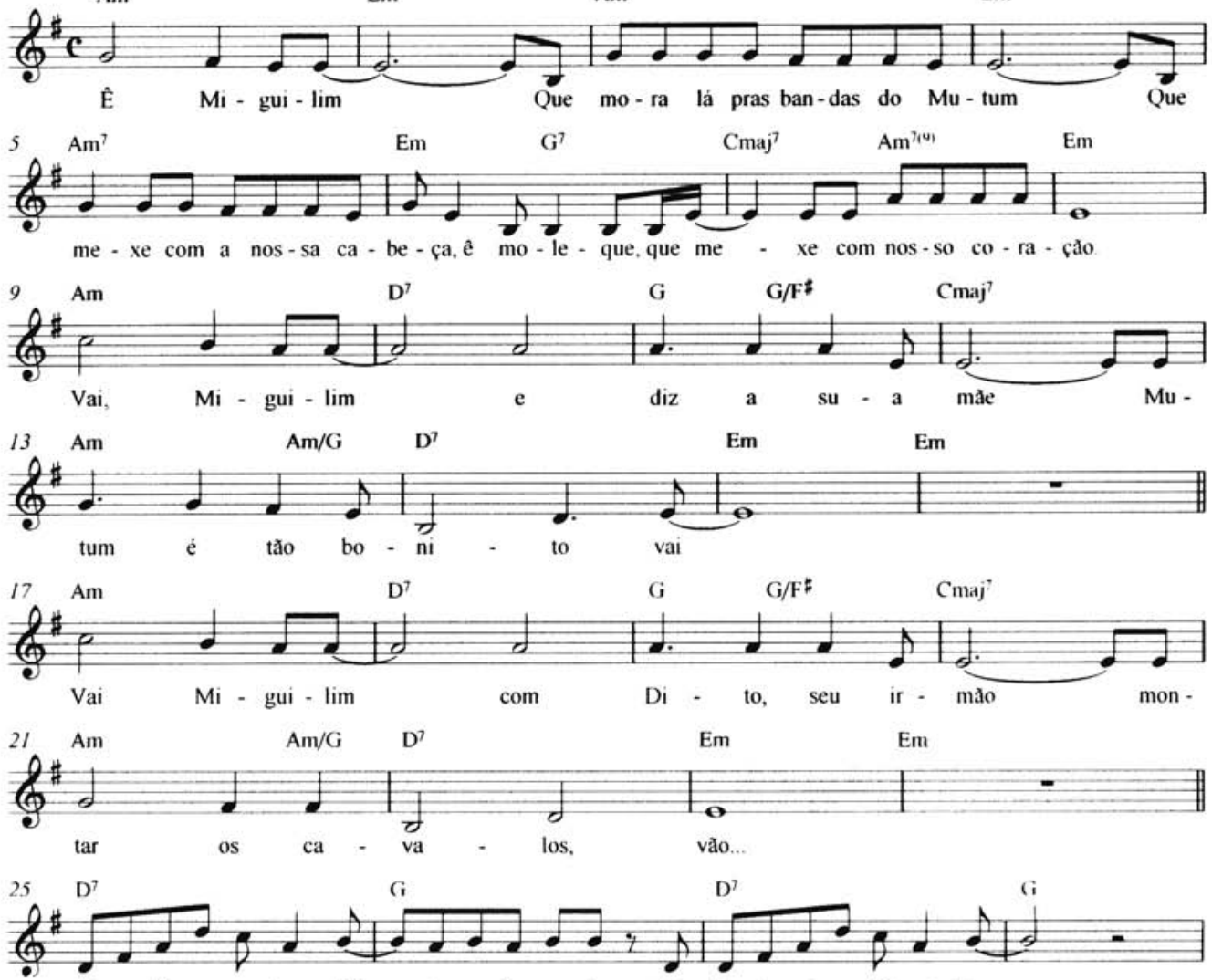

E no $\mathrm{Pa}$-pa-ven-to,o Di - to ga-lo-pan-do No Pre-to vai o Mi-gui lim

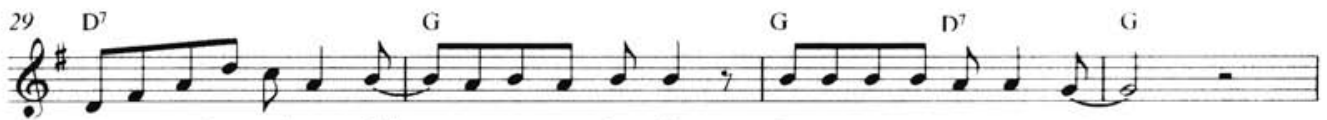

Jé va-quei-ro vai aos dois a-com-pa-nhan-do Pa-ra que não cor-ram as-sım

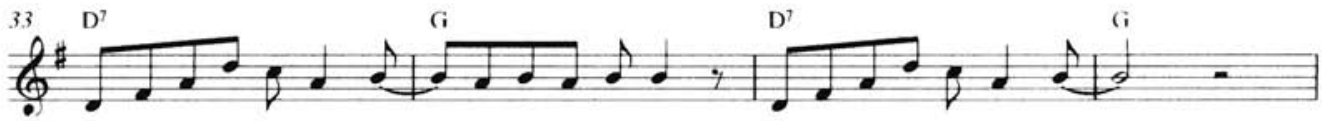

Tan-tas co-res no ca - mi - nho, ga-lo-pan-do mui-to som de pas-sa - rim

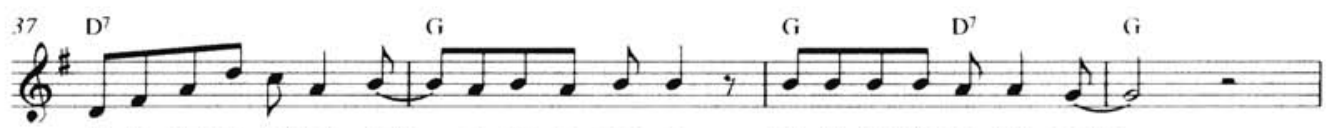

Jé va-quei-ro vai aos dois a-com-pa-nhan-do pa-ra que não cor-ram as-sım.
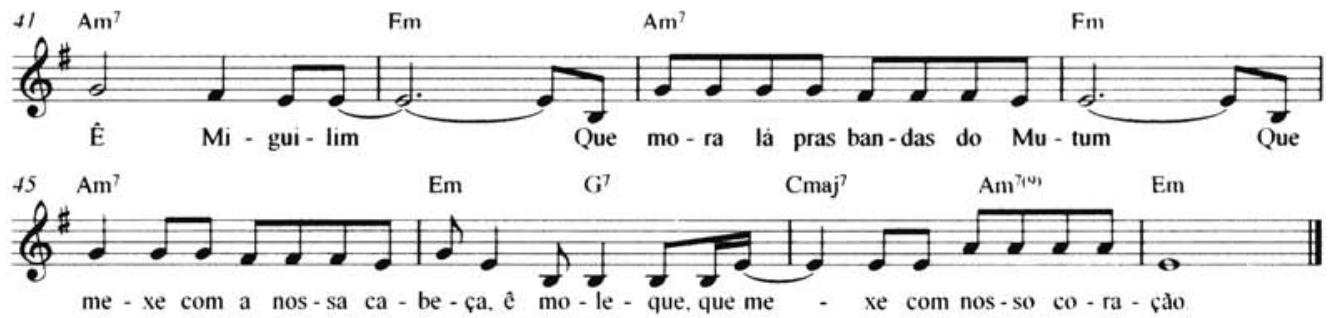

Partitura de Som de passarim, de Wagner Dias, inspirada no conto "Mignilim" de Guimarães Rosa. 
Andrequicé e Cordisburgo-MG em busca da sonoridade dos lugares, das estórias e das personagens de Guimarães Rosa. Fazem shows para público pequeno, em ambiente fechado, com o cenário de casinhas felizes sertanejas. Como outros, confirmam que o compositor e a música são o próprio Joãozito, e que, por isso mesmo, o grupo segue caminho nas interpretações. Daí encontrarem em Curvelo, em roda musical, um certo Miguilim, em motivo de sondagem e de explicação para o sentimento de mãe - coisa de achar lugar Mutum ser tão ruim assim! Se cemiteriozinho, entre vales e montanhas, o Quarteto Estúrdio não soube pôr feiúra nisso - desentendeu o assunto. Os músicos atinaram que o Mutum é lindo de se ver e de se cantar - por toda voz e por todo o canto. Quiseram também que fosse de mais gente ouvir o "agravo". Então, gravaram o "Papaco-o-Paco" e o galope de Dito e Miguilim, lá na Tenda dos Gerais do Andrequicé. A letra da canção, repetidamente, estende-se assim:

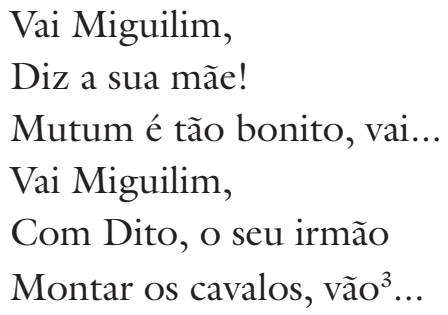

Notas

1 "Assim como o sacrifício de uma vítima (o bode expiatório, que os gregos chamavam pharmakós) quer canalizar a violência destruidora, ritualizada, para sua superação simbólica, o som é o bode expiatório que a música sacrifica, convertendo o ruído mortífero em pulso ordenado e harmônico" (Wisnik, 1989, p.34).

2 Diadorim: no sirgo fio dessas recordações - extraído de Grande sertão: veredas -é também o nome do espetáculo dirigido por Marily Bezerra de Menezes, cujo elenco é formado pelas contadoras de estórias Dôra Guimarães e Elisa Almeida.

3 Canção Som de passarim, de Wagner Dias.

Referências bibliográficas

ROSA, J. G. Sagarana. Rio de Janeiro: Record, 1984. Manuelzão e Miguilim. 9.ed. Rio de Janeiro: Nova Fronteira, 1984. No Urubuquaquá, no Pinbém. 7.ed. Rio de Janeiro: Nova Fronteira, 1984. Grande sertão: veredas. Rio de Janeiro: Nova Fronteira, 1988. Primeiras estórias. Rio de Janeiro: Nova Fronteira, 1988. Magma. Rio de Janeiro: Nova Fronteira, 1997. 
ROSA, J. G. Ave, palavra. 5.ed. Rio de Janeiro: Nova Fronteira, 2001.

.Tutaméia - terceiras estórias. 8.ed. Rio de Janeiro: Nova Fronteira, 2001.

TATIT, L. A. M. O cancionista. 2.ed. São Paulo: Edusp, 2002.

WISNIK, J. M. O som e o sentido. 2.ed. São Paulo: Companhia das Letras, 1989.

Wagner Dias é graduado em Filosofia pela Universidade de São Paulo, músico e compositor integrante do Estúrdio Quarteto. Atua como técnico na Unidade de Produção de Água - MA - da Companhia de Saneamento Básico do Estado de São Paulo (Sabesp). @ - paceolin@ig.com.br

Recebido em 22.9.2006 e aceito em 26.9.2006. 